ISSN 0066-5061

\title{
LAS TESIS DE LOS FILÓSOFOS DEL SIGLO XIII QUE AFIRMARON LA EXISTENCIA DEL INTELECTO AGENTE
}

\author{
THE THESIS OF THE 13th CENTURY PHILOSOPHERS \\ WHO CONFIRMED THE EXISTENCE \\ OF THE AGENT INTELLECT
}

\author{
JUAN FERNANDo SELLÉS \\ Universidad de Navarra
}

\begin{abstract}
Resumen: En este trabajo se revisan las tesis de relevantes filósofos del s. XIII que defendieron la existencia del intelecto agente en el hombre. En el trabajo se dividen en tres grupos a los pensadores: I) Los que se suelen encuadrar dentro del llamado hilemorfismo universal (Alejandro de Hales, Juan de la Rochela y Mateo de Acquasparta). II) La síntesis entre el agustinismo y el aristotelismo (Pedro Hispano, San Buenaventura, Juan Peckham). III) El aristotelismo depurado y proseguido (San Alberto Magno, Sto. Tomás de Aquino, Ramón Llull).
\end{abstract}

Palabras clave: Intelecto agente humano; Hilemorfismo universal; Síntesis aristotelico-agustiniana; Aristotelismo proseguido.

\begin{abstract}
In this article we review the statements of relevant philosophers of the $\mathrm{XIII}^{\mathrm{eme}}$ century supporting the existence of the human agent intellect. Three groups can be distinguished: I) The universal hylemorphism (Alexander of Hales, John de la Rochelle, Mathew of Acquasparta); II) The synthesis between the augustinianism and the aristhotelism (Peter Hispanus, Saint Bonaventura, John Peckham); III) The purified and advanced aristotelism (Albert the Great, Thomas Aquinas, Ramon Llull).
\end{abstract}

Keywords: Human agent intellect; Universal hylemorphism; Aristhotelism-augustinianism; Advanced aristotelism.

\section{SUMARIO}

Introducción.- I. El hilemorfismo universal: 1. Alejandro de Hales. 2. Juan de la Rochela. 3. Mateo de Acquasparta.- II. Las síntesis entre agustinismo y aristotelismo: 1. Pedro Hispano. 2. San Buenaventura. 3. Juan Peckham.- III. El aristotelismo depurado y proseguido: 1. San Alberto Magno. 2. Santo Tomás de Aquino. 3. Ramon Llull.- Conclusión.

\section{INTRODUCCIÓN}

Como es sabido, el descubrimiento del intelecto agente es aristotélico. Pero el Estagirita fue muy parco en palabras a la hora de describir su 
hallazgo ${ }^{1}$. Sus tesis centrales, comúnmente admitidas en nuestros días, son: a) el intelecto agente es propio del hombre; b) es lo más activo del conocer humano; c) es separado de lo sensible, sin mezcla, inmortal, eterno e impasible; d) procede de fuera (el hombre no se lo ha otorgado a sí mismo), y es lo más divino en nosotros. Estamos, pues, ante lo más activo de la teoría del conocimiento humano, ante la cumbre de la teoría, que es, según el decir de este pensador, la forma más alta de vida ${ }^{2}$.

Por otra parte, el tratamiento que del intelecto agente llevaron a cabo los distintos comentadores aristotélicos anteriores al s. XIII, tanto por parte de los pensadores griegos clásicos (Teofrasto de Eresa, Eudemo de Rodas y Alejandro de Afrodisia), y neoplatónicos (Nicolás de Damasco, Plutarco de Queronea, Plotino, Porfirio, Jamblico, Sofonías, Temistio, Juan Filopón y Simplicio) ${ }^{3}$, como por parte de los pensadores árabes (AlKindi, Al-Farabí, Al-Gazalí, Avempace, Ibn-Tufayl, Avicena y Averroes), por los filósofos judíos (Isaac Israeli, Ibn-Gabirol y Maimónides) ${ }^{4}$, y por algunos cristianos del s. XII como Domingo Gundisalvo, tergiversó la doctrina original del Estagirita.

En efecto, las tesis centrales de estos comentadores fueron las siguientes: a) el intelecto agente es Dios; b) es una "sustancia separada"; c) es el alma de la humanidad, etc. Como se puede apreciar, tales interpretaciones postulaban que el intelecto agente no es propiamente una instancia cognoscitiva humana, sino propia de un ser distinto al hombre (Dios, los ángeles, la totalidad del género humano etc.), realidad que sería quien tendría la misión de iluminar constantemente nuestro conocer superior. De ese modo el conocer humano sería siempre pasivo, pues recibiría continuamente la iluminación de aquel principio. Todas esas visiones aceptan, por tanto, la pasividad del conocer humano, y suponen un intento de ontologizar el intelecto agente, es decir, de extrapolar a una realidad externa al hombre la índole del intelecto agente humano. Sin embargo, el conocer humano es acto en cualquier nivel (diversas operaciones inmanentes, distintos hábitos adquiridos de la razón, diversos hábitos innatos, y en suma, el intelecto

${ }^{1}$ Las palabras de Aristóteles exponen que "puesto que en la naturaleza toda existe por una parte un principio que es como la materia para cada genero de entẹs -y.éste es el que está en potencia respecto de todas las cosas-, y por otra parte existe un principio causal y activo que las produce todas -como el arte por referencia a la materia-, es necesario que en el alma también se den estas distinciones. De hecho, existe, por una parte, el intelecto capaz de hacerse todas las cosas; por otra, el intelecto capaz de hacerlas todas, semejante a la luz (...). Y este intelecto es separado, sin mezcla, impasible, en acto por esencia (...). El agente es superior al paciente (...). Y porque es separado es por lo que sólo es propiamente inmortal y eterno... impasible", De Anima, 1. III, cap. 5 (BK 430 a 10-25). En el libro Acerca de la generación de los animales añade que "el intelecto viene de fuera y sólo él es divino, porque una actividad corporal no tiene nada en común con su actividad", De generatione animalium, 1. II, cap. 3 (BK 736 b 27).

${ }^{2}$ Cfr. ARISTóteles, Ética a Nicómaco, 1. X, cap. 7 (BK 1178 a 6-7).

${ }^{3} \mathrm{Cfr}$. mi trabajo: La crítica tomista a la interpretación griega y neoplatónica del entendimiento, "Intellect et imagination dans la Philosophie Médievale", Actas del XI Congreso Internacional de Filosofía Medieval, Oporto, 26-31 de agosto de 20022, Brepols, Turnhout 2006, vol. III, pp. 1389-1404.

${ }^{4} \mathrm{Cfr}$ mi trabajo: La crítica tomista a la interpretación árabe y judia del entendimiento agente, "Espíritu", LII, n¹28, (2003), pp. 207-226. 
agente), es decir, nunca es pasivo y, además, la raíz de todo el humano conocer radica en el propio ser humano.

Por lo demás, en el s. XIII la negación de este conocer en acto por parte algunos pensadores cristianos fue tan llamativa como radical. En efecto, en esa centuria se pueden distinguir tres grupos de filósofos por lo que respecta a su negación del intelecto agente: I) El agustinismo avicenizante (Guillermo de Auvernia, Roger Bacon, Roger Marston), más seguidores de San Agustín y de Avicena. II) El averroísmo latino (Siger de Brabante, Boecio de Dacia, Juan de Sicca Villa), continuadores de Averroes. Los pensadores de estos dos grupos negaron la existencia del intelecto agente en cada hombre por considerar que sólo Dios, o alguna "sustancia separada", es el intelecto agente. La influencia que éstos recibieron de los filósofos árabes es palmaria. En consecuencia, todos ellos admitieron la pasividad del conocimiento humano. III) Los pensadores que redujeron el intelecto agente a la inteligencia (Roberto Grosseteste, Pedro Olivi, Gonzalo de España) $)^{5}$, quienes defendieron esa tesis por diversos motivos: porque consideraron que el alma es simple y no admite distinciones reales (Grosseteste), o porque si el intelecto agente no es cognoscente y carece de tema apropiado, nos basta y sobra con el posible (Olivi, Gonzalo de España). Ninguno de ellos exime tampoco de pasividad al conocimiento humano.

En este trabajo se pretende describir la recepción afirmativa de la doctrina aristotélica sobre el intelecto agente en las universidades de esa célebre centuria. Según el motivo por el que se afirmó la existencia del intelecto agente en el hombre por parte de los distintos filósofos del s. XIII, se ha intentado agrupar a continuación los diversos pensadores en diversos apartados. No se pretende con ello encasillar a nadie, sino buscar las afinidades doctrinales para hacer más comprensible su doctrina y su distinción con las tesis de los demás. Como fruto de esta reagrupación se ofrecen los tres apartados que siguen.

\section{EL HILEMORFISMO UNIVERSAL}

Como es sabido, esta tendencia filosófica consiste en admitir que toda realidad creada está dotada de materia y forma. En consecuencia, el alma también estaría compuesta de esa dualidad hilemórfica. Por tanto, quien acepte esta doctrina tenderá a interpretar al intelecto agente como forma. Con todo, no fue una tesis novedosa en el s. XIII, sino que su origen es más antiguo, pues, como denunció San Alberto Magno ${ }^{6}$, la defendió

\footnotetext{
${ }^{5}$ Cfr. mi trabajo: Los filósofos del s. XIII que negaron el intelecto agente, "Dar razón de la esperanza", Pamplona, Eunsa, 2004, pp. 1277-1300.

6"Non enim consentimus cum Avicebron, quod anima rationalis composita sit ex materia et forma, sed potius dicimus eam componi ex potentia et actu", San Alberto MAGNO, De unitate intellectus, Opera Omnia, vol. XVII 1, 28, a 6-7. Este error también se lo achaca a Alejandro de Hales: "quod intellectus possibilis esset idem quod materia prima, et hoc iam dixerunt quidam (se refiere a Averroes, De Anima, 1. 3, Crawford, p. 394, v. 217 ss., y 395, v. 240
} 
Avicebrón, la continuó Averroes, y la asumió Alejandro de Hales, de quien pasó a sus seguidores. En este apartado destacan tres filósofos: Alejandro de Hales, Juan de la Rochela y Mateo de Acquasparta.

\section{Alejandro de Hales}

Fue el primer maestro franciscano en la Universidad de París. Como se recordará, el Doctor Irrefragabilis, profesor de San Buenaventura y de Sto. Tomás de Aquino, admitió una distinción real entre el alma y sus potencias, entre su ser y su obrar, entre su esencia y sus potencias. De acuerdo con esta tesis, aceptó que el intelecto agente es parte del alma y que tiene dos misiones, a saber, abstraer y unirse al posible: "nada puede educir las formas inteligibles de la potencia al acto, a no ser que sea un acto de ese género. Por lo cual, abstrayendo las formas inteligibles y uniéndose a ellas, es necesario que exista un intelecto en acto... Con todo, el intelecto agente actúa de doble modo: pues obra abstrayendo y uniéndose con el posible"7. El Doctor Halense tiene a su favor que niega, contra la tesis árabe, que el intelecto agente sea una realidad separada del alma humana, pero tiene en su contra el intento de explicarlo armonizándolo con su hipótesis de que el alma humana está dotada de una composición hilemórfi$\mathrm{ca}^{8}$.

De este modo afirma que "el intelecto agente y el intelecto posible son dos diferencias en el alma racional, una de las cuales, a saber, el intelecto agente está por parte de la forma del alma misma, según que es espíritu. Pero otra, a saber, el intelecto posible, está por parte de su materia" 9 . Admite, en consecuencia, la superioridad del agente sobre el posible, y describe al agente como luz natural (lumen naturale), porque tiene el acto de los inteligibles desde el principio de su creación; remarca - como se ha indicado- su papel abstractivo y su ayuda respecto del posible ${ }^{10}$. Advierte asimismo que recibe la luz del primer agente ${ }^{11}$, a saber, de Dios. A distinción de los comentadores griegos, neoplatónicos, árabes y judíos del Estagirita, ya no llama a Dios "intelecto agente", lo cual supone un avance.

ss), quorum secutus est Alexander, non quidem in commento super librum De Anima, sed in quoddam speciali libello, quem de hoc composuit, et est antiquus error", Ibídem., 30, a 2-6.

${ }^{7}$ Alejandro de HALES, Summa Theologica, ind. IV tract. I, sect. II, q. III, tit. I, cap. II, a. II, Claras Aquas, Typ. Collegii S. Bonaventurae, 1928, vol. II, $451 \mathrm{ab}$. Cfr. Joseph Anton ENDRES, Des Alexander Von Hales Leben und psychologisches Jahrbuch, 1888, pp. 24-25; pp. 203-225; pp. 227-298; Otto KEICHER, Zur Lerhe der ältesten Franziskanetheologen vom Intellectus agens, "Abhandluungen aus dem Gebiete der Philosophie und ihrer Geschichte". Eine Festgabe zum 70 Geburtstag G. Fr. v. Hertling gewidmet, Freiburg, Breis, 1913, pp. 176-177.

${ }^{8}$ Cfr. Odon LotTIN, La composition hylémorphique des sustances spirituelles, "Revue Néoscholastique de Philosophie", 34 (1932), pp. $21-41$.

${ }^{9}$ Alejandro de HALES, ob. cit., 452 a.

10"Intellectus vero agens actu abstrait enim et unit cum possibili", Ibídem.

11 "Ad agente primo illuminatur", Ibídem. 
Con todo, añade que sólo cuando el intelecto agente es iluminado perfecciona al posible.

\section{Juan de la Rochela}

Este franciscano, fue colaborador y sucesor como Magister regens de Alejandro de Hales en la Universidad de París. Conoció bien los escritos de Aristóteles y de San Agustín, así como las tesis neoplatónicas y las opiniones de Avicena sobre el alma humana. Su intento parece, a primera vista, el de un conciliador, pues defiende la simplicidad del alma a la par que destaca la multiplicidad de operaciones; admite la abstracción aristotélica a la vez que la iluminación agustiniana. También es de destacar que, como Alejandro de Hales, distingue en el hombre entre esencia y existencia.

En una de sus obras que lleva por título Summa De Anima enseña que "respecto de la verdad suma y respecto de sus inteligibles que exceden al intelecto humano, se dice por completo que Dios es intelecto agente, y su iluminación es la infusión de la gracia para contemplar las realidades divinas. Pero para conocer esas cosas que están junto a sí, como son las esencias angélicas, sus virtudes, sus operaciones y sus órdenes, el alma requiere la revelación angélica o su instrucción. Y en esta comparación el ángel se puede llamar intelecto agente, en cuanto que es instructivo respecto del intelecto humano... Pero para conocer las realidades inferiores, no se requiere la luz de la inteligencia que es externa a sí, ya que la naturaleza del intelecto humano es superior a las cosas corporales, y superior también a las cosas incorpóreas que están en él mismo como en su sujeto, como las potencias, los hábitos y las afecciones; así, para comprender estas cosas no es necesaria la iluminación de las sustancias separadas, sino que basta la luz interna, que es el intelecto agente, esto es, la fuerza suprema del alma" 12 . Admite, por tanto, la denominación de "intelecto agente" tanto para realidades superiores al hombre que actúan sobre éste (Dios, los ángeles), como para una instancia activa superior propiamente humana. Pero estas denominaciones no son fieles a la doctrina del Estagirita y provocan confusión.

En otra obra, denominada Tratado acerca de la división de las múltiples potencias del alma ${ }^{13}$, escribe que la distinción entre el posible y el

\footnotetext{
${ }^{12}$ Jean de la Rochelle, Summa De Anima, 1. II, cap. 37, ed. T. Domenichelli, La Summa de anima di frate Giovanni della Rochele, Prato, 1882, pp. 292-293. Cfr. L.J. BowMAN, The Developement of the Doctrine of the Agent Intellect in the Franciscan School of the Thirteenth Century, "Modern Schoolman”, 50 (1973), pp. 251-279.

${ }^{13} \mathrm{Cfr}$. J. de la Rochelle, Tractatus de divisione multiplici potentiarum animae "Textes Philosophiques su Moyen Age, ed. critique de P. Michaud-Quantin, XI, Paris, Vrin, 1964 Cfr. sobre este tema: T. DOMENICHELli, ob. cit.; Parthenius MINGES, Die psychologische Summa des Johann von Rupella und Alexander von Hales, "Franziskanische Studien", 3 (1916), pp. 365-378; Cornelio FABRO "La distinzione "tra 'quod est' e 'quo est' nella Summa De Anima di Giovanni della Rochela, "Divus Thomas", 41 (1938), pp. 508-522; Gallus MANSER, Johann von Rupella, ein Beitrag zu seiner Charakteristik mit besonderer Berucksihtigung seiner Erkenntnislerhe, "Jahrbuch für Philos. und Spekulative Theologie", 1912, pp. 290-324.
} 
agente es de naturaleza. Identifica el intelecto pasivo y corruptible con la imaginación, que tiene como soporte orgánico el cerebro. Siguiendo a Aristóteles afirma que el intelecto separable se divide en intelecto posible y agente. Pero separándose del filósofo de Atenas asemeja el primero a la materia y el segundo a la forma (influjo neto del hilemorfimo halense). Añade que el primero es como una tabla despojada de toda pintura, pero susceptible de recibir todas las pinturas. El segundo, como luz que irradia siempre; como luz respecto de los colores referidos a las especies inteligibles $^{14}$. También indica -como en la obra anterior- que el intelecto agente es Dios y son también los ángeles, tesis en que no es fiel al Estagiritita. Pero en el mismo texto añade que el intelecto agente es asimismo algo del hombre: "el que el intelecto agente no es separado de la sustancia del alma, sino que mas bien es alguna diferencia de la virtud intelectiva se prueba por el salmista: señalado está sobre nosotros la luz de tu rostro Señor. Asî pues, está en la parte suprema del alma, y por eso se dice: sobre nosotros está la señal de la semejanza de la luz divina. Por tanto, tenemos impresa la luz desde la creación para conocer los inteligibles. Pero esto es lo que llamamos entendimiento agente... Por tanto, la luz por la que entendemos no está separada de la sustancia del alma" ${ }^{15}$.

Y más adelante, tras reiterar que, en otro sentido, Dios y los ángeles son "entendimiento agente" respecto de nosotros, agrega que "como la naturaleza del intelecto humano es superior a las realidades corporales, superior también a las incorpóreas que están en ella misma como en su sujeto, como las potencias, los hábitos, las disposiciones y afecciones, así para comprender estas cosas no es necesaria la iluminación de las sustancias separadas, sino que basta la luz interna, que es el intelecto agente, virtud suprema del alma" ${ }^{\prime 6}$. De este texto se puede deducir que el intelecto agente humano no se reduce a su tradicional papel abstractivo, pues de él depende asimismo el conocimiento de las potencias, hábitos, disposiciones y afecciones, tesis novedosa y sugerente. Con todo, esto no lo clarifica Juan de la Rochela, pues a continuación concreta que "el intelecto agente tiene dos operaciones, una es la abstracción de los fantasmas de la fantasía...; y otra operación es la recepción de la iluminación de lo Primero" ${ }^{17}$. La primera es luz, la segunda, "espejo". De modo que, por intentar compatibilizar este punto con la teoría de la iluminación agustiniana, deja abierta la puerta a la pasividad cognoscitiva, pues en esa segunda faceta comprende al entendimiento agente respecto de lo Primero como recipiens et possibilis, como la Luna respecto del Sol, tesis netamente aviceniana. En esto se percibe, por tanto, una fluctuación, porque también admite a continuación que las cosas

\footnotetext{
${ }^{14} \mathrm{Cfr}$. Tractatus de divisione multiplici potentiarum animae, ed. cit., 86-87.

${ }^{15}$ Ibídem, p. 90.

${ }^{16}$ Ibídem, p. 91.

${ }^{17}$ Ibídem, p. 91.
} 
que están en el alma no se perciben por abstracción ${ }^{18}$. Además, en cuanto a la recepción de la iluminación angélica, dice que ésta no afecta, como la divina, al entendimiento agente, sino al posible, postulado que sui generis de este autor.

En suma, a distinción de su maestro Alejandro De Hales, Juan de la Rochela vuelve a llamar a Dios -como lo hacían los filósofos árabes"intelecto agente". Es más, amplía esa denominación también a los ángeles. Con todo, tiene a su favor que también alude con esa designación al núcleo del conocimiento humano, y lo caracteriza como "la virtud suprema del alma", elemento que es netamente aristotélico. Otro inconveniente es que lo subsume, como su maestro, en el hilemorfismo universal. Pero si se admite esta teoría, o bien se la toma metafóricamente, o bien se acepta que todo lo creado es con materia y, en consecuencia, que nada se puede explicar sin ella. De modo que el intelecto agente no podrá excluirse de esta vinculación con la potencialidad material, asunto que en modo alguno es aristotélico. Otro inconveniente es que sigue considerando al intelecto agente como una potencia, aunque le llama "luz innata del alma"19, pues entonces no se ve cómo una potencia pueda ser acto nativamente. Esta dificultad será inherente también a la concepción tomista del intelecto agente, pero no es propia de Aristóteles, quien consideró a este intelecto cono el acto (por tanto, no una potencia o facultad) de los inteligibles en acto.

\section{Mateo de Acquasparta}

Este pensador franciscano, natural de Umbría, fue discípulo fiel de San Buenaventura, y un conciliador como Avicena y Juan de la Rochela. Maestro de la Universidad de París más tardío que los precedentes (entre 1275 y 1276). Siguió también la doctrina de San Agustín acerca de la iluminación del alma por parte de Dios, pues, según él, sin esa luz el hombre no podría conocer. Pero para conocer, el alma humana requiere también formar las especies inteligibles por medio del intelecto agente, que permite abstraer. Admite asimismo que el alma se conoce a sí misma, no por abstracción, sino tras la abstracción, postulado que es muy interesante, pues obviamente el alma no se puede conocer por abstracción, ya que no es sensible. Sus descripciones del intelecto agente son certeras, muy semejantes a las de Tomás de Aquino. Sin embargo, acepta, como Alejandro de Hales y Juan de la Rochela, el hilemorfismo universal, hipótesis que ni es aristotélica ni correcta, pues el conocer es, por definición inmaterial, precisamente porque es acto, mientras que la materia es siempre de orden potencial.

Tras rastrear diversas opiniones habidas al respecto, este filósofo declara que "hay otra posición más sana, verdadera y conveniente, que toda sustancia creada, ya sea corporal o espiritual, está compuesta de materia

\footnotetext{
${ }^{18}$ Cfr. Ibídem, p. 94.

${ }^{19}$ Ibídem, p. 91.
} 
y forma" 20 . Acepta esto porque, al margen del género de lo sustancial (compuestos hilemórficos), sólo admite el ser de Dios. Pero si, en rigor, una sustancia es un compuesto de causa material y formal, y se admite que toda realidad -salvo el ser divino- es de orden sustancial, toda realidad tendrá esa composición. Como se puede apreciar, el modelo sustancialista (tan querido para Averroes), arquetipo que está tomado de la realidad física y que es aplicable exclusivamente a ella, pesa en exceso en este autor. Pero ese paradigma juega malas bazas cuando se saca del ámbito de la realidad física y se atribuye a niveles superiores de la realidad, porque conlleva la fisicalización del conocer humano (algo semejante al modelo explicativo que Kant ofrecerá del conocer humano 5 siglos después).

Entre la producción de este pensador de la Umbría se cuentan unas Quaestines Disputatae de Anima XIII ${ }^{21}$. En la Cuestión VII se pregunta "si existe una sola alma intelectiva para todos los hombres", afirmación propia de algunos árabes. Para responder a esta cuestión comienza distinguiendo entre: a) el intelecto pasivo o imaginación, que es corruptible; b) el intelecto llamado material, incorruptible, que es el posible; c) el intelecto que es luz respecto de la imaginación y del posible, incorruptible, a saber, el agente; y d) el intelecto en hábito, especulativo o formal, que es el entendimiento posible ya informado. Hechas estas distinciones, luego admite que la imaginación es diversa en cada hombre. Asimismo que el intelecto en hábito o especulativo es distinto en cada hombre. Añade que el posible es inmaterial y uno en cada hombre, pues si fuera uno para todos los hombres, dado que el ser es por la forma, y la forma es el posible, todos los hombres serían un sólo ser, y se distinguirían únicamente de modo accidental, lo cual es absurdo y contrario a la fe.

Respecto del agente, acepta que toda su luz cognoscitiva procede de Dios, y en este sentido se puede decir que Dios es agente. Con todo, en cada hombre existe una potencia abstractiva y, por tanto, un intelecto agente, pues "no parece conveniente que en el alma racional, que es a imagen de Dios, no exista algún principio activo por el cual pueda cumplir su natural operación, sino que sea potencia pura. Sin embargo, aunque exista una potencia de este estilo, con todo, no basta sin la ayuda de la luz eterna"22. En consecuencia, para Mateo de Acquasparta el intelecto agente -a distinción de los pensadores árabes- no es uno para todos los hombres, ni es ajeno a los hombres (angélico o divino), sino que se multiplica según la multiplicidad de los hombres. Además, indica que "la posición verdadera y católica es que tanto el intelecto agente como el posible se numeran según la

\footnotetext{
${ }^{20}$ Matthieu d' AcQuasparta, Quaestiones Disputatae De Anima XIII, ed., A. J. GoNDRÁS, Paris, Vrin, 1961, p. 168. Y tras los argumentos que esgrime en defensa de su tesis concluye: "Dicendum igitur omnem substantiam creatam, tam corporalem quam spiritualem, esse compositam ex materia et forma", p. 173.

${ }^{21} \mathrm{Cfr}$. Mateo de ACQuasparta, ob. cit. Cfr. Pasquale Mazzarella, La dottrina dell'anima e della conoszenza in Matteo d'Acquasparta, 1969; Martin GRABMANN, Die philosophische und theologische Erkenntnislere des Kardinals Matthaeus von Aquasparta, Wien, 1906.

${ }^{22}$ Quaestiones Disputatae De Anima, q. VII, ob. cit., p. 125.
} 
numeración de los individuos humanos, ya que uno y otro son la primera perfección del hombre por la cual el hombre es hombre, y aunque comience con el cuerpo..., sin embargo, ya que no depende del cuerpo, corrompido el cuerpo, se separa y permanece viviendo de nuevo" ${ }^{23}$. Esto es netamente aristotélico.

Añade que tanto el intelecto posible como el agente, por ser creados, son limitados; que son la perfección primera del hombre, es decir, aquélla por la que el hombre es hombre; que la operación propia del hombre es entender; que la multitud de los hombres se causa por la multiplicación de las formas (intelectivas o perfecciones primeras en cada hombre) que se multiplican por las diversas materias; que la multitud de los hombres no se causa por la multitud de formas imaginadas. Por último, que "así como es doble el acto de la luz, así es doble el acto del intelecto agente. Uno es el acto primero, esto es, lucir; otro el acto segundo, a saber, iluminar. En cuanto al acto primero, que es como lucir, siempre entiende, y no entiende alguna vez y no entiende alguna otra vez; en cuanto al acto segundo, que es como iluminar, no siempre entiende, incluso según Aristóteles y Avicena, ya que ni el posible recibe siempre, ni el agente abstrae siempre. Este ejemplo lo pone expresamente Agustín en el libro X De Trinitate, donde dice que el alma siempre se recuerda, siempre se conoce, siempre se ama, lo cual no se puede entender en cuanto al acto segundo, que es discernir y considerar, ya que no está siempre en acto de entender, sino en cuanto al acto que está en aptitud, y que en cuanto de sí depende, siempre está en acto, como la luz luce siempre, y no siempre ilumina" ${ }^{24}$. Estas últimas tesis son muy interesantes, pues llevan a cuestionar si un acto como lo es el intelecto agente puede tener pluralidad de operaciones o más bien ser un sólo acto. Asimismo, si se trata de un único acto, cabe preguntar si su tema debe ser asimismo único. Si se responde afirmativamente a estas cuestiones habrá que averiguar cuál es la índole de tal acto y cuál es su tema. A la par, habrá que negar que sea propio del intellectus agens la pluralidad operativa propia de la abstracción, diversidad que se deberá atribuir a otra instancia cognoscitiva.

En su Quaestiones de fide et cognitione $e^{25}$ el Acquaspartense escribe que el intelecto agente para Aristóteles es un hábito ${ }^{26}$. No obstante, aunque el Estagirita lo asemejó a un hábito intelectual, no lo identificó con esa realidad noética. El pensador de Umbría acepta asimismo que es una $l u z^{27}$, un

\footnotetext{
${ }^{23}$ Ibídem, p. 130.

${ }^{24}$ Ibídem, p. 135.

${ }^{25} \mathrm{Cfr}$. Matthaei ab ACQUaSPARTA, O.F.M., Quaestiones disputate de fide et cognitione, ed. $2^{\mathrm{a}}$, Collegii S. Bonaventurae, Quaracchi, Florentiae, 1957.

${ }^{26}$ Cfr. Ibídem, P. 225, 3. Cfr. asimismo: Quaestiones Disputate De Gratia, ed. Victorin DouCET, Claras Aquas, Typ. Colegii S. Bonaventurae, 1935, p. 171.

${ }^{27}$ "La luz del intelecto agente es como la luz connatural al ojo, pero la luz divina es como la luz solar", p. 243, 29; p. 260, 3; p. 264, 25.
} 
principio asimilativo ${ }^{28}$. También que su oficio es abstraer las especies de los fantasmas ${ }^{29}$, es decir, ser acto respecto de ellas, pero de un modo peculiar, pues las ilumina a la vez (simul) que las especies están en el intelecto posible, y a la inversa ${ }^{30}$. Admite no sólo que el agente ilumina los fantasmas $^{31}$, sino también al mismo intelecto posible ${ }^{32}$, confortándolo, vigorizándolo, ilustrándolo.

En suma, Mateo de Acquasparta describe al intelecto agente con unas notas que son propiamente aristotélicas, a las que añade otras afines a los comentadores aristotélicos del s. XIII, pero no se libra del lastre del hilemorfimo universal. En consecuencia, hay que concluir que para este pensador el intelecto agente es como la forma respecto del cuerpo ${ }^{33}$. Pero esa tesis no es aristotélica. Tampoco correcta, porque el conocer humano no es causal. Una cosa es que el conocer se compare a la causa formal (analogía que acepta el mismo Tomás de Aquino), y otra muy distinta que se identifique con ella, aunque en este caso se entienda que se trata de una causalidad muy sutil, pues si el conocer causase, ya no se podría aceptar la correcta sentencia medieval según la cual "el ser conocida es una denominación extrínseca para la realidad física".

\section{LAS SÍNTESIS ENTRE AGUSTINISMO Y ARISTOTELISMO}

En este grupo también observamos la influencia agustiniana y avicenista. Pero a distinción de los autores encuadrados en el epígrafe precedente, a los que siguen se les nota una impronta aristotélica más aguda. Con todo, el suyo no responde a un aristotelismo puro, sino a una lectura agustiniana de la filosofía del Estagirita. En efecto, el modelo aristotélico se intenta hacer compatible con la teoría de la iluminación agustiniana. En este apartado se atenderá al pensamiento de Pedro Hispano, San Buenaventura y Juan Peckham sobre el intelecto agente.

\section{Pedro Hispano}

Estudió en París, fue profesor en Siena, y llegaría a ser Papa con el nombre de Juan XXI. En 1277, desde la sede apostólica romana, se lamen-

\footnotetext{
28“Y el principio asimilativo es el intelecto agente, que es como luz", Ibídem, p. 260, 3. Cfr. asimismo: p. 219, 10; p. 233, 6.

${ }^{29}$ Cfr. Ibídem, p. 211, 5; p. 213 4; p. 264, 1; pp. 272 ss; pp. 283-286; p. 302; p. 318, 22.

${ }^{30}$ Cfr. Ibídem, p. 269, 27.

${ }^{31}$ Cfr. Ibídem, p. 251,13 ; p. 269, 23; p. 273, 10; p. 276, 1.

${ }^{32}$ Cfr. Ibidem, p. 273, 2; p. 334.

33 "Est alia positio firma et vera tam secundum philosophiam quam secundum theologiam, quam secundum fidem rectam, quod spiritus intellectualis unitur corpori, non sicut carceri nec șicut motor tantum mobili, sed sicut forma materiae et sicut perfectio perfectibili, ita quod ex eis fit vere unum, non tantum in agendo, sed etiam in essendo", Ibídem, p. 30. Como se aprẹcia, abandona a Platón y sigue a Aristóteles, pero sigue al Estagirita según la impronta de Álejandro de Hales.
} 
taría de las innovaciones doctrinales introducidas por algunos profesores en la Universidad de París, pidiendo al obispo Esteban Tempier información sobre tales doctrinas ${ }^{34}$. Pero, como es bien conocido, el obispo parisino, omitiendo la información, actuó por su propia cuenta apresuradamente. El resultado de su intervención también es conocido: la condena de ciertas tesis tomistas en 1277.

Este pensador lusitano fue médico, filósofo y teólogo insigne. Contó con escritos de medicina, lógica, filosofía y teología. Pero fue uno de los filósofos que más estudió el alma humana. Por eso, tiene en su haber, entre otros muchos escritos, un comentario al De Anima de Aristóteles titulado Expositio libri de anima ${ }^{35}$, escrito alrededor de 1245, primer comentario latino a esa obra aristotélica. A ese comentario se atribuyen dos códices distintos (uno de Madrid más breve, con comentarios a los tres libros; y otro de Cracovia más extenso, con comentarios a los dos primeros libros, con 26 lecciones que comprenden 225 cuestiones). Se supone que ambos comentarios correspondan a cursos diversos de Pedro Hispano sobre el alma. Cuenta también con otro libro extenso sobre el alma, Scientia Libri De Anima $^{36}$, dividido en 13 tratados y 108 capítulos, posterior a los dos aludidos textos que comentan el De Anima del Estagirita.

En su filosofía se da una combinación de la teoría de la iluminación agustiniana con tesis avicenianas ${ }^{37}$, y con tesis franciscanas. Lo primero, el agustinismo, porque admite unas ideas innatas a modo de vestigios o semillas, y porque acepta también una intelligentia separata, Dios, que interviene en todos los actos intelectuales del hombre, algo así como la teoría de la iluminación agustiniana. Ésta inteligencia contiene todas las formas o ideas, pues las crea; es una luz más íntima que la propia inteligencia humana y la ilustra infundiéndole tales formas cuando el alma se une cognoscitivamente a aquella inteligencia ${ }^{38}$. Lo segundo, el influjo de Avicena, porque admite la impresión de las causas primeras, los ángeles, en el intelecto agente. Lo

\footnotetext{
${ }^{34}$ Cfr. A. MoreIRA DE SÀ, Pedro Hispano e a crise de 1277 da Universidade de Paris, "Boletin da Biblioteca da Universidade de Coimbra", 22 (1954), pp. 1-21.

${ }^{35} \mathrm{Cfr}$. para los comentarios a los libros I y II De Anima: Manuel Alonso, Pedro Hispano, Obras Filosóficas II, Commentario al "De anima" de Aristóteles, ed. Madrid. CSIC, Inst. Fil., Luis Vives, Serie, A, no 3, 1944. Cfr. para los comentarios a los libros I-IIII: M. ALONSo, Pedro Hispano, Obras Filosóficas, III, Expositio libri de anima, ed., Madrid, CSIC, Inst. Fil., Luis Vives, Serie, A, no 4, 1952.

${ }^{36}$ Cfr. Pedro Hispano, Scientia Libri De Anima, ed., M., Alonso, Madrid, CSIC, Inst. Fil., Luis Vives, Serie, A, n⿳ 1, 1941. De esta obra se entresacan los textos concernientes a los dos intelectos en el artículo de Martin GRABMANN, Die Lehre vom Intellectus possibilis und Intellectus agens im Liber De Anima Petrus Hispanum, des späteren Papstes Johannes $X X I$, "Archives d'Histoire Doctrinale et Littéraire du Moyen Age", 11 (1937-38), pp. 167208. Cfr. asimismo: O. MARTINS, O "De Anima" de Pedro Hispano, "Revista Portuguesa de Filosofía", VIII (1952), pp. 260-294.

${ }^{37} \mathrm{Cfr}$. José FERREIRA, Presença do Augustinismo avicenizante na teoria dos intellectos de Pedro Hispano, Pontificiom Athenaeum Antonianum, Facultas Philosophiae, Theses ad Lauream, 39. Braga 1959; Joaquín CARRERAS, Historia de la Filosofía Española, Filosofía cristiana de los $s$. XîII al X'V, vol. I, Madrid, 1939, p. 140.

${ }^{38} \mathrm{Cfr}$. Pedro HisPano, Scientia Libri De Anima, cap. septimum: De intelligentia agente separata, ed. M. ALONSO, Madrid, 1941, pp. 445-450.
} 
tercero, lo peculiar de la escuela franciscana, porque acepta en el alma una composición entre materia y forma ${ }^{39}$.

En el Comentario al "De Anima" de Aristóteles, manuscrito de Cracovia, en las cuestiones que sirven de preámbulo, pregunta si la potencia que permite que el alma se conozca a sí misma es el intelecto posible o el agente. Responde que el conocimiento que el alma tiene de sí misma es doble: a) una por reflexión sobre sí, y esto es propio del intelecto agente, y b) otra por reflexión sobre otras cosas, y en ésta actúan aquello por lo que se conoce, el agente, y aquello que recibe, el posible ${ }^{40}$. Estas tesis son muy interesantes, profundas, y parecen carecer de precedentes, lo cual nos indica que estamos ante un pensador agudo. Por su parte, en la Expositio libri De Anima, manuscrito de Madrid, asume que es propio del intelecto agente abstraer, y del posible recibir lo abstraído ${ }^{41}$, tesis común en todas las épocas. Más adelante comenta el pasaje aristotélico clave del libro III $D e$ Anima en el que el Estagirita distingue el agente del posible. Pedro Hispano entiende que Aristóteles considera el agente como cierto hábito, que es separable, inmixto, impasible, en acto, más noble que el posible, "sustancia en acto", que entiende a la vez que el posible, que no entiende temporalmente, que es separable del cuerpo ${ }^{42}$. Rechaza la opinión de Averrores por suponer éste pensador árabe al agente y al posible existentes al margen del hombre, pues -según el pensador lusitano- ambos intelectos forman parte de la naturaleza humana. Luego compara el agente a la luz y al sello, y el posible a los colores y a la cera. Admite además que no es necesario que todo lo que se entiende sea imaginado antes, como tampoco es necesario que todo lo imaginado sea antes sentido ${ }^{43}$, opiniones brillantes, verdaderas, pero que se alejan de nuestro tema de estudio.

En cuanto a su Scientia Libri De Anima, en el tractatus X, capítulo $\mathrm{V}$, estudia la naturaleza del intelecto posible, y en el VI, la del agente. En este libro sigue manteniendo que el intelecto agente ilustra al posible favoreciendo la abstracción y adaptando el acto de la inteligencia; lo sigue comparando a la luz. Añade que el posible tiene una doble inclinación: en una está acomodado al régimen de lo corpóreo, en otra, al agente. Por su parte, el agente también tiene dos vías operativas: una es la de la abstracción (las esencias universales); otra, la de elevarse a la contemplación superior, es

39“Anima dupliciter consideratur: Uno modo in quantum est perfectio et sic est forma, et sic eam accipit Aristoteles in principio secundi. Alio modo secundum quod est substantia, et sic est composita ex materia spirituali et forma, nec est simplex forma tantum, sed est forma et substantia quae est hoc aliquid composita", Comentario al De Anima de Aristóteles, 1 . I, lec. tertia, M. AlLONSO, Pedro Hispano, Obras'Filosóficas, II, Madrid, CSIC, 1944, p. 252.' Y en otra obra: "sicut ens sensibile duo habet in se, scilicet, materiam et formam, similiter et ens spirituale duo habet in se, quorum unum est materiale et reliquum formale", Expositio libri De Anima, M. Alonso, Pedro Hispano, Obras Filosóficas, III, Madrid, CSIC, 1952, pp. 228229.

${ }^{40}$ Cfr. Ibídem, p. 72.

${ }^{41}$ Cfr. M. Alonso, Pedro Hispano, Obras Filosóficas, III, Madrid, CSIC, 1952, p. 314.

${ }^{42}$ Cfr. Ibídem, pp. 322-323.

${ }^{43}$ Cfr. Ibidem, p. 332. 
decir, el inclinarse a la comprensión depurada de las realidades espirituales ${ }^{44}$ (esto es, de las sustancias separadas), recibiendo la impresión de las causas primeras (Dios y los ángeles) imprimiéndolas a su vez en el posi$\mathrm{ble}^{45}$. Como se ve, en este filósofo se da una oscilación respecto a elucidar del tema propio del intelecto agente, pues, por una parte, no quiere evadir la sentencia común respecto de la abstracción, pero, por otra, sugiere referir el intelecto agente a las realidades espirituales como a su tema propio. Tal intelecto -amplía- es la virtud pura, más sublime, más cercana al creador, y se ordena de modo más conforme a su conocimiento ${ }^{46}$. Acepta pues, en contra del averroísmo, que el intelecto agente y el posible son dos virtudes propias del alma, pues emanan de su esencia. El agente es virtud incorpórea, sin órgano, y por eso, separable; infinita en su acción, la más elevada de las potencias, acto del posible, y distinto de él por varios motivos: a) por naturaleza, pues mueve al posible; b) por estado, pues es separado de las facultades sensibles; c) por orden, pues lo activo precede a lo pasivo; y d) por accidentes, pues no requiere de hábitos ${ }^{47}$. Su conocimiento, comprensión intensa, es continuo, mientras que su irradiación sobre el posible no lo $\mathrm{es}^{48}$. Lo difícil, no sólo para este autor -que no lo intenta-, sino para la posteridad, será compatibilizar ambas tesis: ¿cómo una misma instancia cognoscitiva puede caracterizarse por ser un acto continuo, a la par que admitir la intermitencia, aunque ésta quede referida a una función menor?

Las descripciones del intelecto agente por parte del Doctor Hispano son muy agudas y muy no pocas de ellas bien ajustadas a la realidad. Pero intenta aunar la excelencia que predica del intelecto agente no sólo con el iluminismo agustiniano, sino también con las tesis avicenianas de la impresión de las causas primeras en el intelecto agente, y eso ni es aristotélico, ni tampoco correcto, porque sobre la raíz de todo el conocer humano sólo puede incidir el Creador, ya que es éste de quien depende la donación de tal conocer humano originario.

\section{San Buenaventura}

El célebre Doctor Seraphicus tuvo mucho influjo de San Agustín ${ }^{49}$, pero estudió bien a Aristóteles. Con el primero comparte la teoría de la

\footnotetext{
${ }^{44}$ Ibídem, p. 439. Y más adelante: "(intellectus agens) ad res vero supremas separatas elevat aspectum, cuius officio sola anima eas in sua consistentia comprendere nata est", Ibídem, p. 444 .

${ }^{45}$ Cfr. P. Hispano, Scientia Libri De Anima, ed., M. Alonso, Madrid, CSIC, Inst. Fil., Luis Vives, Serie, A, no 1, 1941, pp. 430-437.

${ }^{46}$ Cfr. Ibídem, p. 440.

${ }^{47}$ Cfr. Ibídem, p. 443.

${ }^{48}$ Cfr. Ibídem, p. 444.

${ }^{49} \mathrm{Cfr}$. Pierre MANDONNET, L 'Augustinisme bonaventurien, "Bulletin thomiste", 1 (1926), pp. $48-54$
} 
iluminación divina ${ }^{50}$. Con el segundo, la innegable existencia en nosotros del intelecto agente. En efecto, este franciscano acepta la distinción real entre el intelecto agente y el posible en el hombre. En su exposición parte de resumir qué han pensado los filósofos precedentes respecto de la distinción de ambos intelectos, pues unos los distinguían como dos "sustancias", otros como dos "potencias", unos terceros como el "hábito y la potencia", y un último grupo como "una potencia absoluta y otra comparada".

Dentro de la primera opción, es decir, la de quienes consideraban que ambos intelectos se distinguen como "dos sustancias", Juan Fidanza distingue dos vertientes: a) La de los que decían que el agente era una sustancia separada inferior a Dios mientras que el posible era una sustancia unida al hombre (éste era el parecer de Al-Kindi, Al-Farabí, Avicena, Avicebrón, Algazel, Maimónides ${ }^{51}$, etc.). Pero este modo de distinción lo considera erróneo, pues ninguna sustancia, salvo el mismo Dios, puede iluminar inmediatamente al alma humana. b) La de los que en esa distinción sustancial identificaban el intelecto agente con Dios y el posible con nuestra alma (era el caso de Avempace ${ }^{52}$, Averroes, etc.). Pero también esto lo considera falso, porque Dios nos ha dado una virtud activa, por la cual podemos ejercer nuestras propias operaciones. Por ello, "hay que creer indudablemente que no sólo se diese al alma humana el intelecto posible, sino también el agente, así uno y otro son algo del alma"53.

En la segunda opción, la de quienes distinguían el agente del posible como "dos potencias", se ha interpretado, a su vez, -sigue el santo Doctor- de dos modos: a) Que el posible era una potencia puramente "material", y el agente una potencia puramente "formal" (era la opinión -como hemos visto- de Alejandro de Hales, Juan de la Rochela y Mateo de Aquasparta). Pero este modo de decir, declara, non consonat veritati, porque de ese modo el posible habría que ponerlo en todos y cada uno de los sentidos que tienen soporte material, lo cual es absurdo. b) Que el agente y el posible son "dos diferencias" del intelecto, es decir, "de una única sustancia", ya que el posible está ordenado a tomar de las especies, y el agente a abstraerlas (era el parecer de Guillermo de Auvernia, Roberto Grosseteste, Pedro Olivi y Gonzalo de España). Ahora bien, para San Buenaventura ni

${ }^{50} \mathrm{Cfr}$. V. Ch. BIGI, La dottina della luce in S. Bonaventura, "Divus Thomas", 64 (1961), pp. 395-422. También comparte con el obispo de Hipona el ejemplarismo. Cfr. 'M. BISSEN, L'exemplarisme divin selon saint Bonaventure, "Etudes de Philosophie Medievale", 10, París, 1929.

${ }^{51}$ Cfr. Juan Fernando ORTEGA, El entendimiento agente en Maimónides, "Revista Española de Filosofía Medieval", 9 (2002), pp. 63-79.

${ }^{52}$ Cfr. Joaquín LomBA, El lugar del intelecto agente el pensamiento de Avempace, "Revista Española de Filosofía Medieval’, 9 (2002), pp. 33-48.

${ }^{53}$ SAn BuENAVENTURA, In II Sententiarum, d. 24, p. 1, a. 2, q. 4, ed. Quaracchi, vol. II, p. 568. Cfr. Vicente MUÑIZ, La iluminación del entendimiento agente en San Buenaventura, "Revista Española de Filosofía Medieval", 9 (2002), pp. 81-90. Bonifaz Anton, LUYCKX, Die Erkennislehre Bonaventuras, Beiträge, XX'III, 3-4 (1923), pp. 66-76 y p. 223; Karl WERNER, Die Psychologie und Erkennislehre des hl. Bonaventuras, 1876; Eduard LuTZ, Die Psychologie Bonaventuras, 1909; Ciriaco MORÓN ARROYO Abstraction und illumination. Grenzproblem der Mataphysik Bonaventuras, 1963; Etienne GILSON, La filosofía de San Buenaventura, Buenos Aires, Descée de Brouwer, 1948. 
el posible es puramente pasivo, ni el agente es del todo activo, pues no puede conocer si no es ayudado por las especies. Por lo cual, "ni el posible entiende sin el agente, ni el agente sin el posible" ${ }^{4}$. Y este modo de decir, sigue manifestando, verus est, pues ambos concurren a un acto.

El tercer modo de interpretar la distinción entre ambos intelectos, sigue sintetizando el pensador toscano, es la de quienes toman a uno como potencia y al otro como hábito. A su vez, esta posición también admitió históricamente dos lecturas: a) la de quienes compararon al agente a un hábito innato y el posible a la potencia. Esta opinión Juan Fidanza la atribuye a los seguidores de Boecio, pero también parece que fue la opinión de Temistio. Éstos pensaban, en consecuencia, que el agente es innatamente cognoscitivo. Pero este modo de ver, replica, no concuerda con lo que dice el Filósofo, pues afirmó que el alma es como una tabula rasa, que no tiene nada habitualmente conocido, sino que lo adquiere todo mediante el sentido y la experiencia. b) La de quienes compararon el agente a un hábito de la potencia, que sería el posible, en el sentido de que el agente fuese potencia habitual (este parecer lo apoya en Aristóteles, quien dejó escrito que el agente es "como un hábito"). Y este modo de decir, indica, probabilis est et verus.

El cuarto modo de distinguir ambos intelectos, señala el Doctor Seráfico, es el de quienes dicen que uno de ellos es una potencia absoluta y el otro una potencia comparada. Y, asimismo, esto se puede entender de dos modos. a) De uno, según que se tome a los dos como una única potencia, con una mera distinción de comparación, pues el agente se tomaría en sí mismo, mientras que el posible se tomaría en cuanto que se une al cuerpo y a los fantasmas (este parecer también se puede fundar, dice, en Aristóteles, quien escribió que el agente "siempre está en acto", mientras que el posible "a veces sí y otras no". Pero ese modo de decir, nos indica, deficit $a$ veritate, porque el alma separada tiene intelecto agente y posible, y es claro que el posible no se dice tal en esa situación por comparación al cuerpo. b) De otro modo, en el sentido que el agente se tome como potencia absoluta o completa, porque no le falta nada, y el posible como comparada o requerida de complemento, porque se ordena a tomar.

La opinión bonaventuriana de que el agente y el posible concurren inseparablemente fue compartida por Tomás de Aquino, hasta el punto que éste último sostiene que el agente nada puede conocer sin su concurrencia con el posible. Además, San Buenaventura vincula tanto el intelecto agente a su papel abstractivo, que acaba admitiendo que sin las realidades sensibles y sin los sentidos es imposible conocer: "si el agente puede formar o abstraer el conocimiento en el intelecto posible, sin embargo, su operación depende tanto de la certeza de la realidad externa como del sentido interior;

${ }^{54}$ Ibídem, vol. II, p. 569 a. 
ya que faltando la realidad perece la ciencia, y faltando el sentido, es necesario que falte la ciencia según aquel sentido" 55 .

La rectitud del pensador toscano es grande, pues no se quiere pronunciar por ninguna opinión sin haber examinado antes todas las que se han dado y ha podido conocer respecto de este tema, examinando bien sus dificultades. Su fidelidad al Estagirita también le caracteriza, pues rechaza las opiniones sustancialistas del intelecto agente de todo tipo (las que lo identificaban con las "sustancias separadas", con Dios, con el hilemorfismo); admite, como Aristóteles, que posible y agente no pueden ser dos funciones de una misma potencia; que aunque el agente se compare a un "hábito" o a una "potencia", en rigor, no es de esa índole; etc. Pero San Buenaventura no sabe a fin de cuentas cómo resolver la cuestión, sencillamente porque la resolución del problema no cabe dentro del esquema usual que se tenía de la filosofía aristotélica, a saber, que lo que no era de orden sustancial debía ser considerado de orden accidental. Pero a Juan Fidanza no le parece convencer este rígido esquema para explicar el intelecto agente, y con razón, puesto que ni el intelecto agente es sustancia, ya que entonces se podría entender como ontológicamente separado (visión árabe), ni es accidente, ya que si es lo más alto del conocer humano, y la raíz y fin de todo otro conocer del hombre, y el conocer (junto con la voluntad) son lo más alto y distintivo de lo humano ¿cómo se va a considerar un accidente?

\section{Juan Peckham}

Fue maestro de teología en París y siguió a Roberto Kilwardby en la sede episcopal de Canterbury. Este franciscano fue tan agustinista como su predecesor en la cátedra ${ }^{56}$, y como él, se opuso a Aristóteles y a Tomás de Aquino ${ }^{57}$. Para nuestro propósito son interesantes sus obras De humanae cognitionis ratione ${ }^{58}$, y el Tractatus De Anima ${ }^{59}$. Seguidor de Alejandro de Hales, de Roberto Grosseteste y de San Buenaventura, rechazó las tesis de

\footnotetext{
${ }^{55}$ San Buenaventura, Commentarius in Ecclesiasten, c. VII, Claras Aquas, Typ. Collegii S. Bonaventurae, 1893, vol. VI, p. 54 b.

${ }^{56}$ Cfr. A. CAllebaut, Jean Peckham, O.F.M., et l'augustinisme. Apercus historiques (1263-1285), "Archivum Fratrum Praedicatorum;, 18 (1925), pp. 441-472; Th. CROWLEY John Peckham, O.F.M., Archbishop of Canterbury, versus the New Aristotelianism, "Bulletin of the John Rylands Library", 33 (1951), pp. 242-255; D.L. DouIE, Archbishop Peckham, Oxford, 1952; F. EHRLE, John Peckham über den Kampf des Augustinismus und Aristotelismus in der zweiten Hälfte des drezehnten Jahrhunderts, "Zeitschrift für katholischen Theologie", 13 (1889), pp. 172-193; A TEETAERT, Jean Peckham, "Dictionaire de Théologie Catholique", vol. XII, (1933), cols. 100-140.

${ }^{57} \mathrm{En} 1285$ se lamenta de que por más de 20 años la nueva doctrina aristotélica se haya introducido en el campo teológico con gran detrimento de la tradición agustiniana. Cfr. A. MASNOVO, ob. cit., I, p. 50.

${ }^{58} \mathrm{Cfr}$. Juan PECKHAM, De humanae cognitionis ratione, Anécdota quaedam Seraphici Doctoris $S$. Bonaventurae et nonnumllorum ipsius discipulorum, Quarracci, 1883.

${ }^{59}$ Cfr. J. PECKHAM, Tractatus De Anima, por G. Melani, Pontificium Athenaeum Antonianum, Fac. Philosophica, Tesis ad Lauream, 1949; Johanns Pechami Quaestiones tractantes de anima, ed. Hieronymus SPETTMANN, Beiträge zur Geschichte der Phlophie und Theologie des Mittelalters, XIX pp. 5-6, Münster, 1918. Cfr. del mismo autor: Die Psychologie de Johannes Pecham, 1917, Beiträge zur Geschichte der Philosophie des Mittelalters, p. 20.
} 
Averroes sobre la unicidad del entendimiento agente y posible. Refutó asimismo la tesis de Avicena acerca del entendimiento agente como una criatura separada. A Tomás de Aquino le negó el que el intelecto agente de cada hombre fuese suficiente para conocer. Contra Guillermo de Auvernia y Roger Bacon admitió un intelecto agente creado en cada hombre, pero lo designa como una parte del alma.

En suma, defendió la iluminación divina, al menos para conocer las verdades supremas (influencia agustiniana). Pero intentó compatibilizar esa tesis con la existencia de un entendimiento agente en el hombre (influencia aristotélica), entendimiento al que llama creado $^{60}$. El entendimiento agente se distingue del posible, aunque ambos pertenecen al alma, como dos virtudes o fuerzas, no como dos potencias, pues el alma es única y en ella lo racional no admite división de potencias (influjo de San Buenaventura). Pero este entendimiento natural, según Peckham, no es suficiente para conocer, pues requiere y está subordinado en todo caso (como el ojo respecto de la luz) al "entendimiento agente" por antonomasia, el divino, al que, según su opinión, se refería Aristóteles en su De Anima: "el intelecto agente del que habla el Filósofo no es ninguna parte del alma, sino Dios, según creo, que es la luz de todas las mentes, del que procede todo entender... (El cual es) inmixto, impasible y conoce siempre todo, cuya sustancia es su acción. Y por tanto, mejor lo expuso Avicena que aquellos que lo establecen sólo como parte del alma"61 (influencia reconocida de Avicena). Como se puede apreciar, en esta posición no es fiel al Estagirita, pues éste declaraba explícitamente en su De Anima que posible y agente son distinciones reales del "alma" humana.

En la lectura de la obra de Juan Peckham, de la confluencia entre el intelecto agente divino y el humano surge una paradoja semejante a la ya aflorada al examinar la teoría del conocimiento de Guillermo de Auvernia, a saber, ¿cómo es posible que nuestro conocer sea agente, es decir, activo, si es iluminado por el intelecto agente divino? Sin embargo, esto no le produce ninguna perplejidad a Peckham, porque admite a la vez ambos extremos: "respecto del objeto del intelecto agente digo que el alma tiene en sí algo activo, como una virtud formativa de las especies, como también una virtud judicativa, a saber, de las cosas. Pero aquello que pone al intelecto en acto de inteligir es el intelecto divino" ${ }^{2}$. Como se ve, es una tesis que comporta dificultades que no están resueltas, pues si se admite que el hombre dispone de una sola virtud cognoscitiva intelectual nativamente pasiva, a ésta la debe activar la luz divina. Pero entonces, ¿se debe sospechar que la activa sólo al inicio o siempre? Si se trata únicamente del empujón inicial, en la descripción del hombre no podrá incluirse el ser nativamente intelectual, pues esto sería un don otorgado desde fuera, no un don intrínse-

\footnotetext{
${ }^{60}$ Cfr. Quaestiones De Anima, ed. cit., p. 73, 1. 30; p. 74, 1. 32; p. 75, 1. 18.

${ }^{61}$ Ob. cit., p. 74.

${ }^{62} \mathrm{Ob}$. cit., q. V, p. $68,1.35-38$.
} 
co al ser humano. Si, por el contrario, el conocer humano debe ser iluminado siempre por el divino, a la objeción precedente se añade que lo que el hombre conoce dependería exclusivamente de la iniciativa divina, pero si no es cada hombre el que conoce, sino Dios, ¿cómo podrá ser el hombre responsable?

\section{EL ARISTOTELISMO DEPURADO Y PROSEGUIDO}

Este grupo de filósofos admiten la distinción real entre acto (intelecto agente) y potencia (intelecto posible) en el entender humano. A los pensadores que siguen se les nota un vivo empeño por separar la doctrina aristotélica de cualquier interpretación posterior, sean éstas afrodisianas, neoplatónicas, árabes, judías e incluso agustinianas. También se percibe en ellos un intento de proseguir el hallazgo del Estagirita y no sólo en un trabajo, sino en muchos, asunto que revela, no sólo lo combatido que este tema estuvo en su tiempo, sino también la importancia capital que estos pensadores le conceden.

\section{San Alberto Magno}

El Doctor Universalis estima que Anaxágoras fue el primero que habló del intelecto agente ${ }^{63}$. Su intento de discriminar el verdadero Aristóteles de su comentadores griegos, árabes y judíos (cita y corrige las tesis de Alejandro de Afrodisia, Teofrasto, Temistio, Avempace, Avicena, Teodoro, Algazel, Abubacer, Averroes, Avicebrón, etc.) dio buen resultado por lo que se refiere a perfilar la doctrina aristotélica del intelecto agente, pues mostró la falsedad de la opinión acerca de la unicidad y carácter extrínseco de este entendimiento. También se opuso a otras opiniones extraaristotélicas (Platón, Gregorio Niseno, la de los llamados "latinos" -Pedro Hispano, por ejemplo-, etc.), así como rechazó la teoría franciscana de la composición hilemórfica en el alma ${ }^{64}$.

Cuenta con varios escritos centrados en este tema (De Anima, De intellectu et intelligibili, De naturae et origine animae, De unitate intellec-

${ }^{63} \mathrm{Cfr}$. Albertus MagnUS, Physica, en Opera Omnia, vol. IV, 1, Monasterii Westfalorum in aedibus aschendorff, 1987, p. 171, 62, p. 172, 55. Cfr. sobre este punto: José Angel GARCÍ́A CUADRADO El estatuto del entendimiento agente en la obra de San Alberto Magno, "Revista Española de Filosofía Medieval", 9 (2002), pp. 91-103.

${ }^{64} \mathrm{El}$ intelecto "nec materia est, nec forma proprie loquendo..., nec est corpus neque virtus in corpore et quod est potentia omnia et sic habet aliquid formae et aliquid potentiae et nec est materia neque forma nec compositum proprie, sed potius habet esse..., quod constat ex esse necessario (intelecto agente), secundum quod se habet ad causam primam, et ex esse possibili (intelecto posible), secundum quod est in seipso... Et haec est natura omnis intelligentiae secundae, quae est post primam causam", De unitate intellectus, en Opera Omnia, vol. XVII, 1 , $26,22-32$. 
tus, etc. $\left.{ }^{65}\right)$. Para el magno Alberto la teoría del conocimiento es "el corazón de su pensamiento" "66 , y el quicio de ella, su estudio sobre el intelecto posible y agente. En el De Anima, dedica 19 capítulos al estudio de estos intelectos. En ellos admite, contra Alejandro de Afrodisia, que el posible no es la forma del cuerpo organizado que tiene la vida en potencia, pues está separado no sólo del cuerpo, sino también de los inteligibles ${ }^{67}$. Esto último es un buen desarrollo de la propuesta aristotélica, pues si es separado, no se requiere traer a colación los abstractos para explicar su índole. Por su parte, contra Averroes sostiene que el agente no es separado del hombre. Éste es realmente distinto del posible, y es, además, cognoscitivo, matiz por lo demás obvio, pero que olvidan muchos comentadores aristotélicos de todos los tiempos. Ambos intelectos son separados de la materia, es decir, inorgánicos ${ }^{68}$. Pero ambos se dan en cada hombre, pues son $p o-$ tencias o partes de su alma ${ }^{69}$. Esta posición, en cambio, sigue siendo problemática, al menos referida al intelecto agente, pues es difícilmente compatible con que sea un acto nativo.

Algo similar encontramos, aunque más explícito, en la Quaestio de intellectu animae donde aclara que "sin prejucio me parece que el intelecto agente y el posible son dos potencias del alma, y que el alma está compuesta de "aquello por lo que es" y de "lo que es", que es su composición esencial, de la cual fluye la segunda composición de las potencias del alma. Y de la parte "por lo que es" se causa el intelecto agente, de la parte de "lo que es" el intelecto posible"70. Esta distinción real entre acto y potencia en el alma, que luego recogería Tomás de Aquinoo ${ }^{71}$, es muy importante, pues permite colocar al intelecto agente en el orden del actus essendi del hombre y al posible en el plano de la essentia hominis. Y eso es claramente un avance respecto de la doctrina aristotélica sobre la distinción real entre acto y potencia en toda realidad, al margen del Acto Puro.

Los capítulos centrales del De Anima albertino, al menos para nuestro propósito, son el 18, titulado "Sobre la naturaleza del intelecto

\footnotetext{
${ }^{65} \mathrm{Cfr}$. De Anima, en Opera Omnia, ed. cit., vol. VII/1, 1968; De intellectu et intelligibili, (Borgnet, vol. 9 pp. 477-527); De natura et origine animae, vol. XII, 1955; De unitate intellectus, vol. XVII, 1,1975

${ }^{66}$ Alain de LIBERA, Albert le Grand et la philosophie, Paris, Vrin, 1990, p. 215.

${ }^{67}$ Cfr. De Anima, 1. III, trac. 2, caps. 2 ss.

${ }^{68} \mathrm{Cfr}$. De Anima, 1. III, trat. II, cap. 14: "Digresión que muestra por diez pruebas que el intelecto es separado y sin mezcla"; cap. 15: "En el que se prueba que el intelecto no está mezclado con el cuerpo, por el hecho de que su impasibilidad no es la misma que la impasibilidad del sentido".

${ }^{69} \mathrm{Cfr}$. G. De MATTOS, L intellect agent personnel dans les premiers écrits d'Albert le Grand et de Thomas d'Aquin, "Revue Neo-Scholastique de Philosophie", 1940 (43), pp. 145161; E. GILson, L'âme raisonable chez Albert le Grand, "Archives d'Histoire doctrinale et littéraire au Moyen Age”, 1945 (XIV), pp. 5-72.

${ }^{70}$ Quaestio de intellectu animae, en Opera Omnia, ed. cit., vol. XXV, 2, 269 b 59-270 a 6.

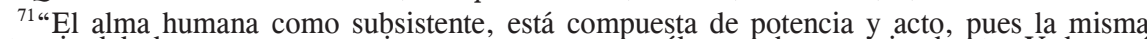
sustancia del alma no es su ser sino que se compara a él como la potencia al acto. Y de aquî́ no se sigue que el alma no pueda ser forma del cuerpo, ya que incluso en estas formas eso que es como la forma, como el acto, en comparación a una cosa, es como potencia en comparación a otra", Cuestiones Disputadas De Anima, q. única, ar. 1, ad 6.
} 
agente y cómo está compuesta el alma", y el 19, cuyo encabezamiento es: "Sobre la comparación del intelecto posible y el agente y el especulativo". En el cap. 18 compara el agente al arte y a la luz en tanto que hace que las formas en potencia sean formas en acto (separándolas de la materia y de sus condiciones), y las plasma en el posible. No admite que el agente sea cierto hábito, aunque tenga semejanza con él, ya que por él obra el alma cuando quiere sin necesitar de otro. Pero sí reconoce que sea separado e inmixto, como el posible. Es, además, impasible, y en esto difiere del posible. Añade que "es sustancia, que es acto" 72 , y que es más noble que el posible. En el cap. 19 escribe que "son dos las obras del agente, una de las cuales es abstraer las formas inteligibles, que no es otra cosa sino hacerlas simples y universales, y lo segundo es iluminar al intelecto posible, como la luz se refiere a lo diáfano, ya que es necesario que la especie universal, mientras que es universal, siempre esté en la luz del agente; y por eso, cuando se recibe en el intelecto posible, es necesario que se reciba en la luz del agente, y por eso es necesario que el posible sea iluminado con la luz del intelecto agente" ${ }^{73}$.

Por otra parte, acepta que el posible sea, en cierto modo, anterior según el tiempo al agente en cada hombre, aunque no lo precede de modo universal, pues no le precede en orden de importancia, ya que el agente es $a c t o$, y el acto siempre es anterior que la potencia. Sostiene que, debido a su separación, ambos intelectos son inmortales y perpetuos "permaneciendo junto al alma también cuando (ésta) hubiese salido del cuerpo"74, pues "cuando el intelecto está completamente separado, que es la conversión del intelecto posible al agente, que tiene todo su entender dentro de sí mismo, entonces no recuerda" ${ }^{75}$ sensiblemente, se entiende; y podríamos añadir que tampoco imagina, ni hace proyectos concretos de futuro, ni ve, ni oye, etc. Por tanto, el entender del posible tras esta vida es distinto que en ella, pues aquí usa de los sentidos (internos y externos), más no en la otra vida. Admite también que "el intelecto agente es forma del posible, y estos dos son como un compuesto, pero sus operaciones son diversas" ${ }^{76}$.

Por otra parte, en el tractatus tertius del mismo libro III De Anima titula el cap. 11 "Digresión que declara la verdadera causa de la unión del intelecto agente con nosotros", y San Alberto escribe que en esta cuestión él no hace sino imitar a Aristóteles "cuando dijo que así como en toda naturaleza en la que se da el paciente, también (se da) el agente, así es necesario que se den en el alma estas diferencias. Pues por esto nos parece, y no dudamos de que el intelecto agente no sea parte y potencia del alma, pero diciendo que él es parte, estará unido siempre, sin duda, al alma como par-

\footnotetext{
${ }^{72}$ De Anima, 1. III tract. 2, cap 18, ed. cit. p. 204, b 65. Esto lo repite en el De unitate intellectus, en Opera Omnia, vol. XVII, 1, p. 26 b 82.

${ }^{73}$ Ibídem, cap. 19, p. 205 b 65-75.

${ }^{74}$ Ibídem, p. 206 a 15.

${ }^{75}$ Ibídem, p. 206 a 22-25.

${ }^{76}$ Ibídem, p. 206 b 76-78.
} 
te"77. Alberto Magno está de acuerdo también en este capítulo con Alfarabí, para quien el agente es más separado que el posible, y que lo separado no se une a menos que exista una causa de la unión.

Describe al agente de modo muy peculiar, pues expresa que él mismo "es su luz, por el hecho de que su luz es su esencia y no está fuera de sí mismo"78. Esta descripción es genial, pues en ella se ve claro que para describir la índole de lo superior, el agente, no es pertinente hacerlo depender de lo inferior, del posible. Explica que la unión del agente con nosotros es de tres modos: "por naturaleza se une como potencia y cierta virtud del alma, pero haciendo los inteligibles especulativos se une como eficiente, y de estas dos uniones no resulta el hombre perfecto, hasta que se obre la obra divina. Se une a la par como forma, y la causa de aquella unión es el intelecto especulativo; y por eso es necesario que haya especulativo antes que adepto"79. El especulativo, para Alberto, no es exactamente lo mismo que el posible, sino - como él declara- un "instrumento" del agente, pues si no se pone este intermediario, "ya que el agente es una y simple esencia, no puede ser causa suficiente de la distinción de las especies en el especulativo; por eso, el especulativo es su instrumento para distinguir el intelecto posible" 80 . De modo que admite entre el posible (potencia) y el agente (acto) cierto instrumento, algo así como lo que Tomás de Aquino llamará hábitos innatos, que son la habilitas o el instrumento del intelecto agente.

En este libro expone, por último, que el intelecto agente proviene de fuera, declarando así su procedencia divina; se une al hombre de modo admirable, y según este intelecto el hombre se hace semejante en cierto modo a Dios, por el hecho de que puede obrar de modo divino y tomar todos los inteligibles en cierto modo. Es lo más propio del hombre y del que hay que predicar aquello del Estagirita según lo cual todos los hombres desean por naturaleza saber. De acuerdo con esto, no se le puede considerar como un accidente del hombre, sino como algo radical suyo. Además, de él se debe predicar asimismo la libertad, pues entiende cuando quiere; la sutileza; e incluso la santidad y la profecía ${ }^{81}$, tesis novedosas en las que le siguió Tomás de Aquino.

El De natura et origine animae es posterior a los precedentes escritos albertinos, porque los cita. En éste texto se defiende que no puede haber un solo intelecto para todos los hombres ${ }^{82}$, error al que cedieron Averroes y Abubacer ${ }^{83}$, pues de ser así -añade San Alberto-, también habría una sola naturaleza vegetativa, sensitiva, nutritiva, etc., para todos los

\footnotetext{
${ }^{77}$ De Anima, 1. III, tract. 3, cap. 11, ed. cit., p. 221 a 21-29.

${ }^{78}$ Ibídem, p. 222 a 1-3.

${ }^{79}$ Ibídem, p. 222 a 15-24.

${ }^{80}$ Ibídem, p. 222 b 68-72.

${ }^{81}$ Cfr. Ibídem, p. 222 b 79- 223 a 34.

${ }^{82} \mathrm{Cfr}$. De natura et origine animae, tract. I, cap. 5, ed. cit., vol. XII, p. 14, 11.

${ }^{83}$ Cfr. Ibídem, cap. 6, p. 15, 46.
} 
hombres, lo cual le parece un absurdo digno de risa. En este punto se percibe que el principio de individuación humana, para San Alberto (como después para Sto. Tomás), no corre sólo a cargo de la materia, es decir, del cuerpo humano, sino sobre todo del espíritu, en concreto, en este caso, del intelecto. En efecto: "es este intelecto otro individuo por el ser, en el que termina el hombre, y lo vegetativo y lo sensible que hay en él mismo" 84 . Sigue admitiendo que en el alma se dan dos intelectos: el posible y el agente ${ }^{85}$. El posible "no tiene ninguna comparación a la materia" ${ }^{86}$. Tampoco el agente, pero éste segundo se sigue comparando con la luz; se acepta su papel abstractivo, y se le declara más perfecto que el posible, al que mueve ${ }^{87}$, siendo "el primer agente y motor en toda la naturaleza" 88 .

En la Summa de creaturis añade que "el intelecto agente es una cierta inteligencia (...), que intelige su esencia. (...). El intelecto agente intelige mejor su esencia que a los otros inteligibles" ${ }^{\text {" }}$. Por su parte, en las Quaestiones super De animalibus reitera que su origen es extrínseco ${ }^{90}$, pues procede -como reiterará Tomás de Aquino- directamente de Dios; que el agente es como luz, y su conocer es un estar-en-sí-mismo. Por lo demás, sigue manteniendo su papel abstractivo de los fantasmas.

En el opúsculo De unitate intellectus (posterior a su De Anima, al De intellectu et intelligibili y al De natura animae et generatione), arremete contra la hipótesis de la unidad y separación del intelecto agente tal como era postulada por los averroistas. Lo escribió contra éstos, quienes sostenían que tras la muerte del hombre sólo permanece un intelecto para todos. La obra se divide en un proemio y tres partes. La primera consta de $30 \mathrm{ob}-$ jeciones; la segunda, de 30 argumentos en contra de ellas; y en la tercera se expone la solución que da Alberto y su respuesta a las objeciones de la primera parte. Vayamos a alguna de las claves de la solución.

Por un lado, entiende al alma como una sustancia de la que emanan unas potencias, de las cuales unas son separadas y otras unidas al cuerpo. Las primeras están en el alma por semejanza de la causa primera (Dios), causa por la cual ellas están en el alma ${ }^{91}$, y ya que derivan y tienen como fin a esa causa y no derivan de la generación se puede decir que el intelecto

\footnotetext{
84 "Est autem intellectus hic aliter individuus per esse, ad quod terminat hominem, et vegetabile et sensibile, quod est in ipso", Ibídem, cap. 7, p. 16, 69-71.

${ }^{85}$ Cfr. Ibídem, cap. 7, p. 16, 2 y cap. 16, p. 43, 54.

86"Nullam materia comparationem habet”, Ibídem, cap. 7, p. 16, 22.

${ }^{87}$ Cfr. Ibídem, cap. 16, p. 43, 55 .

88 "Primum movens et agens in tota natura", Ibídem, cap. 16, p. 43, 75.

${ }^{89}$ Summa De Creaturis, II ps., trac. I, De Homine, q. 55, a. 6.

${ }^{90} \mathrm{Cfr}$. Quaestiones super De animalibus, ed., Filthaut, pp. 280-282.

91 "Quod intellectus est causatum luminis causae primae, verum est”, Ibídem, p. 26 b 71. "Ab ipsa substantia animae fluit potentia illa quae vocatur intellectus possibilis, et sicut genus est designatio materiae cum potentia ad esse, ita possibilis intellectus est designatio talis substantiae in anima, et intellectus agens designatio est illius naturae sive substantiae, secundum quam ut ens necesse dependet ad primam causam per quam tenetur in esse necessario", $I b i$ dem, p. 28 b, 61-68.
} 
es eterno ${ }^{92}$. La segundas están en el alma según que es alma, es decir, acto del cuerpo. El intelecto agente pertenece a las primeras; el posible tiene que ver con las segundas ${ }^{93}$. Por otra parte, indica que el alma tiene tres ámbitos de saber o tres "theorias": la "philosophia prima", según la luz del entendimiento agente; la "mathematicam", según la conversión a la imaginación; y la "physicam", según la conversión a los sentidos (esquema que aprovechará Tomás de Aquino en su escrito In Librum Boetii Super de Trimnitate). La que depende directamente de la causa primera, precisamente por ello, es acto puro, y "según esto está en ella el intelecto agente" 94 . En cambio, la que en ella es potencia es el posible. El agente informa al posible con su luz. Informado el posible, tiene junto a sí, por aquella luz, el intelecto de los principios, que los tenemos naturales, no aprendidos ${ }^{95}$. De modo que, al igual que admitirá su discípulo de Aquino, el hábito de los primeros principios es innato e instrumento del entendimiento agente para activar al posible. Remata el texto concluyendo que sólo este entendimiento agente es el verdadero y no otro (a saber, no ese otro descrito por los comentadores aristotélicos precedentes), "y este intelecto que se compone así de los inteligibles para la forma y acto del intelecto mediante los principios, que tiene junto a sí, según mi opinión se llama especulativo" ${ }^{96}$.

\section{Santo Tomás de Aquino}

Este ilustre dominico, tiene, entre otras alusiones indirectas, 9 escritos referidos al intelecto agente. En efecto, trató de este tema en el Comentario a las Sentencias ${ }^{97}$, las Cuestiones Disputadas sobre la Verdad ${ }^{98}$, varios lugares de la Suma Contra los Gentiles ${ }^{99}$, las Cuestiones Disputadas sobre el Alma ${ }^{100}$, el Compendio de Teología ${ }^{101}$, las Cuestiones Disputadas Sobre las Criaturas Espirituales ${ }^{102}$, el Comentario al libro III Sobre el Al-

92 "Si dicatur aeternum, quod nec initium habet nec finem per generationem, quae est super substantiam, quod est materia, et est ens simplex et immobile, hoc modo intellectus est aeternus tam agens quam possibilis, Si autem dicatur aeternum, quod nullo modo per potentiam et actum exivit in esse nec cum tempore nec praeter tempus, hoc modo sola prima causa est aeterna", Ibídem, p. 30, a 27-34.

${ }^{93} \mathrm{Cfr}$. De unitate intellectus, en Opera Omnia, vol. XVII, 1, p. 22, a 1-20. Con todo, el intelecto posible no es material, como admitía Teofrasto: "Nos dicimus, quod est virtus, quae nec est corpus nec in corpore operans et tamen est substantia fundans intellectum agentem", Ibídem, p. 24 b 65. Declara que el posible funda al agente en el sentido de que "haec potentia es fundamentum fundans et recipiens esse, quod est a causa prima", Ibídem, p. 26, 11-13.

${ }^{94}$ Ibídem, p. 22 , b 62.

${ }^{95}$ Cfr. Ibídem, p. 22, b 90.

${ }^{96}$ Ibidem, p. 23, b 30-33.

${ }^{97}$ Cfr. In II Sententiarum, d. 17, q. 2, a. 1.

${ }^{98}$ Cfr. Q.D. De Veritate, q. 10, a. 6.

${ }^{99}$ Cfr. Summa Contra Gentes, 1. II, caps. 76, 77 y 78; 1. III, caps. 42, 43, 44 y 45.

${ }^{100}$ Cfr. Q.D. De Anima, qq. 4 y 5.

${ }^{101} \mathrm{Cfr}$. Compendium Theologiae, lb. I, cap. 83.

${ }^{102}$ Cfr. Q.D. De Spiritualibus Creaturis, q. un., a. 10. 
$m a^{103}$, el opúsculo Sobre la Unidad del Intelecto ${ }^{104}$ contra los averroistas, y en la Suma Teológica ${ }^{105}$. Sin seguir un estudio cronológico ${ }^{106}$, sino más bien temático, se pueden resumir las tesis tomistas sobre el intelecto agente del siguiente modo.

Por una parte, el de Aquino afirma, sin lugar a dudas, que el entendimiento agente existe realmente en el hombre. Declara que es uno según el ser con el hombre, pero uno según el ser sustancial, no según el ser accidental, puesto que ya no sería el entendimiento agente sustancia, sino accidente ${ }^{107}$. Con todo, tras esta drástica afirmación que recuerda a San Alberto, cabe preguntar si tal intelecto será la misma alma. La respuesta tomista es negativa. Entonces, ¿qué es del alma? Tomás de Aquino repite a menudo que es "algo", "parte", "potencia" "accidente" del alma; y, por ello, se funda (como el posible) en la esencia del alma. Por otra parte, como su maestro Alberto, admite que es una potencia humana sin soporte orgánico, distinta del posible, pero que se parece más al hábito que a la potencia (pues se distingue de la privación y de la potencia). Pertenece, pues, a esa parcela del alma que es separada, no dependiente del cuerpo y, por tanto, inmortal y perpetua. Sin embargo, frente a su maestro, el de Aquino no predica de este intelecto la eternidad, sino que empieza a existir con el сиеrpo (es connatural y originario en nosotros), pero sobrevive a él, y sigue conociendo cuando éste perece.

Frente al averroísmo, el Doctor Angélico mantiene reiteradamente que el intelecto agente es uno para cada hombre; personal, por tanto. Pero, a distinción de su maestro, concreta que es forma del alma ("forma ani$\left.m a e^{" 108}\right)$. Acepta asimismo que es una luz cognoscitiva innata, y que por él conocemos todo lo que podemos conocer, pues sin él el hombre no puede conocer nada. Es acto (principio activo propio) y, por tanto, previo y superior, respecto del entendimiento posible (que es potencial). Su acción le es concomitante, pero no existe identidad real entre él y su acción. Con todo, acepta que no siempre conoce, pues declara que no actúa sin su concurrencia con el posible. Sin embargo, esta tesis es problemática porque hace depender la explicación del agente de su vinculación con el posible, que es

${ }^{103}$ Cfr. In De Anima, 1. III, cap. 10.

${ }^{104} \mathrm{Cfr}$. De Unitate Intellectus, caps. I-V

${ }^{105}$ Cfr. S. Theologiae, I ps., q. 79, aa. 3, 4 y 5.

${ }^{106} \mathrm{C}$ fr. sobre punto mi escrito: El entendimiento agente según Tomás de Aquino, "Revista Española de Filosofía Medieval”, 9 (2002), pp. 105-124.

107 "Si por la virtud intelectiva es necesario que el mismo entender del intelecto agente sea el entender del hombre, esto no puede ser a menos que de la sustancia del intelecto agente y de la șustancia del hombre se haga uno según el ser; pues es imposible que si son dos sustancias diversas según el ser, que la operación de una sea la operación de otra. Así pues, el intelecto agente sera uno según el ser con el hombre. Pero no según el ser accidental: puesto que ya no sería el entendimiento agente sustancia, sino accidente... Queda, pues, que el intelecto agente sea uno con el hombre según el ser sustancial. Así pues, o bien será el alma humana o parte de ella, y no alguna sustancia separada", $S$. C. Gentes, 1. İII, cap. 42, n. 7.

108 "Intellectus quoad actum essendi est forma animae, sed quoad actum intelligendi est e converso", De Veritate, q. 10, a. 8, ad 13. Según ello, el intelecto agente hay que ponerlo a nivel de actus essendi. 
inferior a él. Añade que no activa directamente al posible, sino mediante las especies. Él, en cambio, no tiene como algo propio tener o dejar de tener especies, lo cual es propio del posible. El agente no tiene en sí ninguna especie inteligible. Además, no basta él sólo para activar al posible, pues la perfección del posible no se logra tampoco sin Dios. No activa a la voluntad ni directa ni indirectamente, pues ésta es activada por el posible. El que uno entienda mejor o peor que otro no se debe al entendimiento agente de cada uno, sino a la complexión de las potencias con soporte corporal de las que éste abstrae (imaginación, memoria, etc.).

Al igual que San Alberto, acepta que el intelecto agente procede de Dios: "la luz del intelecto agente..., procede en el alma, sin duda, como del primer origen, de las sustancias separadas y principalmente de Dios"109; "luz impresa en nosotros inmediatamente por Dios y según esto discernimos lo verdadero de lo falso, y lo bueno de lo malo"110. Es un desbordamiento en nosotros de la perfección divina; cierta participación de la luz intelectual de las sustancias separadas, en especial de Dios: "virtud derivada del intelecto superior" ${ }^{111}$. Y participa de Dios tanto natural como sobrenaturalmente (y según esto último, tanto la vida presente, por la fe, la profecía ${ }^{112}$ y la gracia, como en la futura, por la gloria ${ }^{113}$ ). Para el Aquinate el intelecto agente muestra la existencia de Dios, pues es necesario que por encima del alma humana exista algún intelecto del que dependa el entender del intelecto agente. Esta última, tal vez sea la tesis más importante de Tomás de Aquino sobre este tema, pues al vincular el intelecto agente con Dios como con su origen y fin, se empieza a entrever que sólo Dios puede ser su tema propio y distintivo.

Vayamos ahora a esa advertencia albertina acerca del eslabón que enlaza el intelecto agente y el posible. Para su discípulo también los hábitos innatos de los primeros principios (teóricos y prácticos) son un instrumento del agente ${ }^{114}$. Además, añade que "los primeros principios prácticos se cap

${ }^{109}$ De Veritate, q. 10, a. 6, co.

110"Unde dicimus, quod lumen intellectus agentis, de quo Aristóteles loquitur, est nobis immediate impressum a Deo, et secundum hoc discernimus vero a falso, et bonum a malo", De spiritualibus creaturis, q. 10, co.

111 “In ipsa (anima) sit aliqua virtus derivata a superiori intellectu, per quam possit phantasmata illustrare. Et hoc experimento cognoscimus, dum percipimus nos abstrahere formas universales a conditionibus particularibus, quod est facere acto inteligibilia", $S$. Theologiae, I ps., q. 79 , a. 4 , co.

112“Cum possuerimus intellectum agentem esse quandam virtutem participatam in animabus nostris, velut lumen quoddam, necesse est ponere aliam causam exteriorem a qua illud lumen participetur. Et hanc dicimus Deum, qui interius docet; in quantum huiusmodi lumen animae infundit, et supra huiusmodi lumen naturale addit, pro suo beneplacito, copiosus lumen ad cognoscendum ea ad quae naturalis ratio attingere non potest, sictut est lumen fidei et lumen prophetiae", Q.D. De Anima, q. un., a. 5, ad 6.

${ }_{113}$ “Es propio de Dios iluminar a los hombres imprimiéndoles la luz natural del intelecto agente, y sobre ésta, la luz de la gracia y de la gloria", Compendium Theologiae, I ps., q. 10, ad 1

114 "Es necesario que el intelecto agente se refiera a los principios naturalmente conocidos por nosotros o como el agente al instrumento o como la forma a la materia", S.C. Gentes, 1. III, cap. 43, n. 2. Y añade: "sunt autem quaedam in nobis facta intellecta in actu naturaliter, non ex studio aut ex nostra voluntate, sicut prima intelligibilia. Haec autem facere intellecta 
tan por la luz del intelecto agente..., como también los primeros principios de las ciencias especulativas”115. Además, activa al posible mediante el hábito de los primeros principios. Pero no sólo tiene en cuenta al posible, ya que para conocer se sirve de la potencia cogitativa de la sensibilidad intermedia, potencia que dispone de los fantasmas. De modo que está en acto respecto de las especies sensibles, de las que abstrae, universaliza. Súmese a esto que para Tomás de Aquino el conocimiento de los transcendentales deriva del conocimiento abstractivo generado por el intelecto agente ${ }^{116}$.

Que el agente es de lo más digno de la persona humana parece claro, pues gracias a él el hombre es libre y responsable, y por ello son posibles la ética y la política ${ }^{117}$. Por lo demás, afirma que tras la muerte ya no conocerá como ahora, sino de otro modo ("el alma separada tendrá un modo de entender diferente que el del alma unida"). Si la última felicidad humana es cognoscitiva: "la última bienaventuranza o felicidad del hombre consiste en su operación nobilísima, que es entender, cuya perfección última es necesario que sea por el hecho de que nuestro intelecto se una a su principio activo" "18 , en ella debe estar implicado el intelecto agente. Con todo, en esta vida el intelecto agente no conoce de modo neto a Dios. Tampoco es autointencional o reflexivo, pues no se puede conocer a sí mismo.

Las tesis tomistas sobre el intellectus agens son, en líneas generales, fieles a las aristotélicas, pero suponen un avance doctrinal respecto de ellas, porque se explicita que el intelecto agente es pieza central en el hombre, sobre la que gira la libertad, la responsabilidad, la elevación sobrenatural, la raíz de la ética y política, etc. Además, se le vincula directamente con Dios. Con todo, en los textos tomistas se mantiene todavía una rémora, a saber, que se sigue considerando al intelecto agente como una potencia. Con todo, la doctrina tomista de la distinción real entre actus essendi-essentia ofrece una solución adecuada a este planteamiento gnoseológico aporético, pues si ésta distinción real se descubre en el hombre, se pueden vincular los dos intelectos a las respectivas dimensiones de esa dualidad, haciendo girar así el agente en el orden del actus essendi y el posible en el de la essentia. De acuerdo con esto, ya no se podrá aceptar que el intelecto agente sea una realidad de orden sustancial (el acto de ser es superior a la sustancia), ni tampoco de orden accidental (el acto de ser en modo alguno es un accidente).

actu non contingit per intellectum in habitu, per quem fiunt intellecta in actu ea quae scimus ex studio: sed magis sunt initium intellectus in habitu. Unde et habitum horum intelligibilium ab Aristotele, in VI Ethicorum, intellectus dicitur. Fiunt autem intellecta in actu per solum inte-
llectum agentem".

${ }^{115}$ De spiritualibus creaturis, q. 10, ad 9.

116"Quamvis illa quae sunt prima in genere eorum quae intellectus abstrait a phantasmatibus, sint primo cognita a nobis, ut ens et unum, non tamen oportet quod illa quae sunt prima simpliciter (como Dios), quae non continentur in ratione proprii obiecti, sicut et ista", In Boetii De Trinitate, 1, 1, 3, ad 3.

${ }^{117}$ Cfr. Summa Contra Gentes, 1. II, cap. 76, n. 20.

${ }^{118}$ Ibídem, q. un., a. 5, co. 


\section{Ramón Llull}

Es sabido que tanto Guillermo de Auvernia como San Alberto Magno y Tomás de Aquino se opusieron al averroísmo latino ${ }^{119}$. Pero la primera reacción eclesiástica contra este movimiento la llevó a cabo el obispo de París, Esteban Tempier, en 1270. Con todo, fue en 1277 cuando este obispo condenó 219 tesis, la mayor parte de las cuales se refieren al naturalismo árabe y, por tanto, al averroísmo. Este averroísmo latino incluía en su seno 25 tesis avicenianas. Otras tesis condenadas pertenecían, en cambio, al aristotelismo y a la doctrina de Tomás de Aquino. La misma condena sufrieron ese año tales tesis por parte del obispo de Canterbury, el dominico Roberto Kilwardby. A pesar de ello, los dominicos elaboraron a cabo a fines del XIII y comienzos del XIV una literatura polémica contra el averroísmo y en defensa de la doctrina de Tomás de Aquino, hasta que en 1325 fue canonizado el Doctor Communis y levantada la excomunión de sus tesis por el nuevo obispo de París. En este ámbito de abierta repulsa del averroísmo se encuadran los escritos de Ramón Llull.

Llull cuenta con dos fases de lucha antiaverroísta, una a fines del s. XIII, cuando escribió en 1279 la Declaratio per modum dialogi edita contra aliquorum philosophorum et eorum sequacium opiniones, en la que critica las tesis averroístas del elenco de esos 219 puntos condenados en 1277. Otra, cuando publicó esa misma obra en 1311 con el título de Liber contra errores Boetii et Sigerii. Escribió 17 opúsculos contra el averroísmo latino $^{120}$. En este marco, vamos a considerar únicamente la primera, que se presenta como una obra dialogada escrita entre 1297-1299. Sostiene contra Boecio de Dacia y Siger de Bravante que no existe un único entendimiento, al que llama general, para el género humano: "no conviene que exista un solo intelecto general, de modo que los hombres puedan entender por él las cosas generales, ya que Dios puede crear tal magna potestad, virtud, etc., de conocer por medio del intelecto de cada hombre... Pues si fuese así..., se seguiría mucha inconveniencia, como que el hombre siendo inteligente no entendiera, sino que el intelecto entendiera con el hombre como con un órgano... Por tanto, se sigue que tienes intelecto propio, propia voluntad,

${ }^{119} \mathrm{Cfr}$. A. MASNOvo, I primi contatti di san Tommaso con l'averroismo latino, "Rivista di Filosofia Neo-Scolastica", 16 (1924), pp. 367-375; 18 (1926), 43-55; M. CHOSSAT, Saint Thomas d'Aquin et Siger de Bravant, "Revue de Philosophie", 24 (1914), pp. 553-575; y 25 (1914), pp. 25-52: Carmelo OTTAVIANO, Tommaso d'Aquino.' Saggi contro la dottrina averroistica dell unită dell intelletto, Traducción, prefacio y notas, Lanciano, 1930; U. PUCCI, Tommaso d'Aquino. Trattato dell 'unità dell intelletto contro gli averroisti, 'Traducción, introducción y notas, Torino, 1939; F. SASSEN, Thomas van Aquino en Siger van Brabant, "De Beiaard", 8 (1923), pp. 455-478; Gérard VERBEKE, L'unité de l homme: saint Thomas contre Averroès, "Revue Philosophique de Louvain", 58 (1960), pp. 220-249; J. VINATI, In opusculum Divi" Thomae Aquinatis "De unitate intellectus contra Averroistas" commentaria, "Divus Thomas", 1882-1886, vols. I-III.

${ }^{120} \mathrm{Cfr}$. Ferdinand VAN STEENBERGHEN, La signification de l'oeuvre anti-averroïste de Raymond Llull, "Estudios Lulianos", 4 (1960) pp 113-128. Cfr. asimismo: O. KEICHER, Raymundus Lullus und seine Stellung zur Arabischen Philosophie (Beiträge zur Geschichte der Philosophie des Mittelalters, VII, 4-5), Münster, 1909. Introducción; Ephren LONGPRE, Lulle (Raymond), "Dictionaire de Théologie Catholique", vol. IX, 1926 (1), col. 1072-1141. 
propia memoria, que son potencias de tu alma, que es una parte de ti mismo. Y de ellas usas libremente. Pero si se diese, como tu dices, el que tu fueses instrumento del intelecto, y así (sucediera respecto) de la voluntad y la memoria, tu intelecto sería como el instrumento que el artífice usa según su libertad. Y tu no entenderías libremente..., lo cual es falso, y de esto tenemos experiencia" 121.

A Ramón Llull, como se ve, no le faltaba sentido común. Pero tampoco sentido cristiano, pues añade que "por lo demás..., si el intelecto fuese uno para todos los hombres, la resurrección sería imposible, ya que no puede ser a menos que existan muchos intelectos... Además, te digo, que si existiera un solo intelecto general, habría una sola bondad espiritual general... Y si en todos los hombres existiese una bondad espiritual general, como un intelecto general, la bondad general haría bueno a cualquier hombre, así como el intelecto haría entender a cualquier hombre... De lo que se seguiría que ningún hombre tendría libertad de hacer el bien..., sino que sería un instrumento u órgano movido al bien por la bondad general extrínseca... Y si el hombre hace el mal, es movido así al mal por extrínseca malicia general, como cuando hace el bien y es movido por la bondad general. Y de ese modo, ningún hombre tendría libertad de resistir al pecado, lo cual es falso e imposible y contra la experiencia que tenemos de la libertad... Además, el intelecto del que tu hablas, sería eterno. Y ya hemos probado en muchos lugares que nada es eterno sino Dios. Por tanto, queda probado que son muchos los intelectos de los hombres"122.

"El intelecto agente que te hace entender -sigue más adelante Llulles propiamente tuyo, de modo que tu propiamente entiendas por él" ${ }^{123}$. Y añade: "si el intelecto agente no es esencial para mí, o para ti o para otro, no me puedo mover por mí mismo a conocer la primera causa, sino que tal movimiento (ejercido) por un extraño sería violento... De donde se seguiría que Dios no tendría gracias para mí... lo cual es inconveniente y contra la justicia divina... Y para que tal inconveniencia no exista, se sigue que el intelecto agente esté unido con el intelecto posible, y que a la vez sean un intelecto"124. Se subraya "un intelecto", porque, como se advierte, Llull reafirma la unidad en cada intelecto humano, ya que para él agente y posible conforman un único entendimiento en cada hombre, pues no actúan el uno sin el otro. Por lo demás, sigue admitiendo como algunos predecesores, que el objeto propio del intelecto son los universales que se abstraen de la imaginación despojando lo particular de aquellas especies.

\footnotetext{
${ }^{121}$ Ramón Llull, Declaratio Raymundi, per modum dialogi edita contra aliquorum philosophorum et eorum sequacium opiniones erroneas et damnatas a venerabili Patre Domino Episcopo Parisiensi, (también llamada Liber contra errores Boetii et Sigerii) Corpus Christianorum, Continuatio Medievalis, vol. LXXIX, cap. 32, Turnholti, Brepols, 1989, pp. 298-300.

${ }^{122}$ Ibídem, pp. 299-300.

${ }^{123}$ Ibídem, cap. $115,351$.

${ }^{124}$ Ibídem, cap. 118,352 .
} 
En suma, para el pensador mallorquín el intelecto humano es una potencia única en cada hombre, nueva en él, espiritual, inmortal, que se ejerce con libertad, y que dispone de varios momentos o fases. Otras ventajas de la propuesta llulliana estriban en que el intelecto está vinculado a la libertad y a la bondad. Y asimismo, que no es una sustancia. Con todo, si no es sustancial, para Llull, al igual que sostenía Tomás de Aquino, no queda más posibilidad de que sea una potencia, y por tanto, un "accidente", porque si fuera sustancia, el hombre sería tal sustancia, y consecuentemente, no podría tener más potencias. Además, si fuese sustancia, el hombre sería como Dios y se entendería a sí. También por no ser así, es por lo que el intelecto agente puede ser movido por Dios ${ }^{125}$. Como se puede apreciar, lo que le parece estar en juego a Ramón Llull en la interpretación averroista del intelecto agente es la responsabilidad personal, tema al que este caballero medieval no puede renunciar.

\section{CONCLUSIÓN}

En apretada síntesis hay que concluir que el grupo de pensadores que aceptaron el hilemorfiemo universal (Alejandro de Hales, Juan de la Rochela, Mateo de Aquasparta), admitieron la existencia de un intelecto agente en cada hombre, pero lo concibieron como la forma respecto del posible, que vendría a ser como la materia. Pero si el agente no se puede dar separado de la materia, no se ve cómo pueda ser acto, es decir, sin $p a-$ sividad.

Los filósofos que intentaron una síntesis entre el agustinismo -iluminismo- y el aristotelismo (Pedro Hispano, San Buenaventura, Juan Peckham), también afirmaron la existencia del intelecto agente en el hombre. Pero algunos de ellos (los dos primeros) admitieron que es una potencia del alma. El tercero, que en el alma no hay distinción de potencias, pero que el agente es una especie de virtud del alma. Divergen entre sí al considerar al entendimiento agente como algo activo o pasivo. Así, para el primero el intelecto agente es una potencia activa, la más alta, y propia del hombre. Para los restantes, en cambio, parece que el entendimiento agente no esté enteramente eximido de pasividad. Con todo, en estas propuestas tampoco se acaba de ver -ni siquiera en el caso de Pedro Hispano- cómo se puede admitir que el intelecto agente sea a la par una potencia y que sea activo, pues la noción de potencia implica pasividad.

Para los filósofos que se han agrupado dentro del llamado aristotelismo depurado y proseguido (San Alberto Magno, Sto. Tomás de Aquino y Ramón Llull) el intelecto agente existe en el hombre. Lo entienden también como una potencia del alma. Con todo, hay una serie de progresos en su interpretación, de entre los cuales se pueden destacar, al menos, los que

\footnotetext{
${ }^{125}$ Cfr. Ibídem, caps. 119-128, 355-359.
} 
siguen: 1) Si el intelecto agente es aquello "por lo que el alma es", se puede emplazar en el orden del actus essendi humano. 2) No es hábito, sino un acto que usa de hábitos nativos. 3) No sólo abstrae, sino que ilumina al posible. 4) Procede directamente de Dios. 5) De él se predican la luz, la libertad, la sutileza, la felicidad, la fe, la profecía, la santidad y el lumen gloriae. 6) Según Alberto Magno el intelecto agente entiende su propia esencia, pues su conocer es un "estar-en-sí-mismo". En cambio, según Tomás de Aquino, no se puede conocer a sí mismo. 7) Por ello, según el de Aquino, carece de identidad real, de modo que en él habrá que distinguir lo superior de lo inferior, lo más activo respecto de lo menos. 8) Gracias a él el hombre es libre y responsable, y por ello son posibles la ética y la política. 9) Es inmortal y tras esta vida conocerá de otro modo que ahora.

No es poca la información que disponemos sobre el intelecto agente hasta el s. XIII. Si ésta se criba, encontramos, junto a unas tesis poco certeras, otras muy correctas, aprovechables y proseguibles. De entre estas últimas se puede destacar una: emplazar el intellectus agens en el orden del esse hominis. De llevar a cabo esta propuesta, no se podrá erradicar del acto de ser humano su carácter cognoscente y, a la par, como ningún conocer carece de tema, habrá que indagar cual es el tema propio del ser humano como acto de ser cognoscente.

Fecha de recepción del artículo: agosto 2006.

Fecha de aceptación y versión final: noviembre 2007. 